\title{
Supply chain management in the aspect of globalization
}

\author{
Zdenka Vidrova ${ }^{1, *}$ \\ ${ }^{1}$ University of Zilina, Department of Economics, Univerzitna 1, 01026 Zilina, Slovakia
}

\begin{abstract}
The world of logistics has also changed considerably thanks to globalization. The most important term of logistics is the supply chain (SC). With the advent of globalization, managing SC activities has become more complex. Supply chain management (SCM) is an integral part of most businesses and is essential to company success and customer satisfaction. Supply chains (SCs) represents the paths between suppliers and buyers (customers or consumers). The role of (SCs) is to ensure a product from inception all the way into a consumer's hands. Marketing plays an increasingly important role in the process; it balances procurement by providing essential demand information and building the relationships that help improve the efficiency of SC operations. In order to reach as many markets as possible, these products must cross international borders. Without SCs, the products that suppliers produce would not efficiently get out into the world markets - therefore are vital for markets all over the world. The aims of the paper are following: to define the concept of SC and SCM, to list what advantages arising from participation in global supply chain and finally, to refer the mistakes made by companies operating in international markets in SCM.
\end{abstract}

\section{Introduction}

For the past was typical to produce and sell products locally - it was the most economical way to do it. In the case, goods travelled long distances, they were too expensive for many to afford. When transportation became more economical and labour rates climbing in more developed countries, much more manufacturing has moved where cost is lowest. Especially for concrete reason - our world is becoming more and more interconnected. As global markets grow increasingly efficient, competition no longer takes place between individual businesses, but between entire value chains.

Over the last 100 plus years of the history of supply chain management has evolved from an initial focus on improving relatively simple, but very labor-intensive processes to the present day engineering and managing of extraordinarily complex global networks [1].

The following section provides basic definitions of supply chain and supply chain management, also describes the relationship between supply chain management and globalization. Then the methodology is described, followed by the results of the analysis. Finally, the research findings and implications for theory and practice are highlighted.

* Corresponding author: zdenka.vidrova@fpedas.uniza.sk 


\subsection{Basic definitions}

\subsubsection{Supply chain}

[2] describes supply chain as a network of multiple relationships where value can be added. These relationships are schematically represented in Fig. 1 [3]. They can be between processes, products, companies and industries as elaborated upon by $[4,5,6]$. Figure 1 represents following: At the bottom of the value chain hierarchy there are reduced complexity and value added activities. Moving up the chain to the industry level, there is increased complexity and value added activities.

From the foregoing, we can derive another definition of the supply chain: it is the integration of information and resource flows through a series of value added activities.

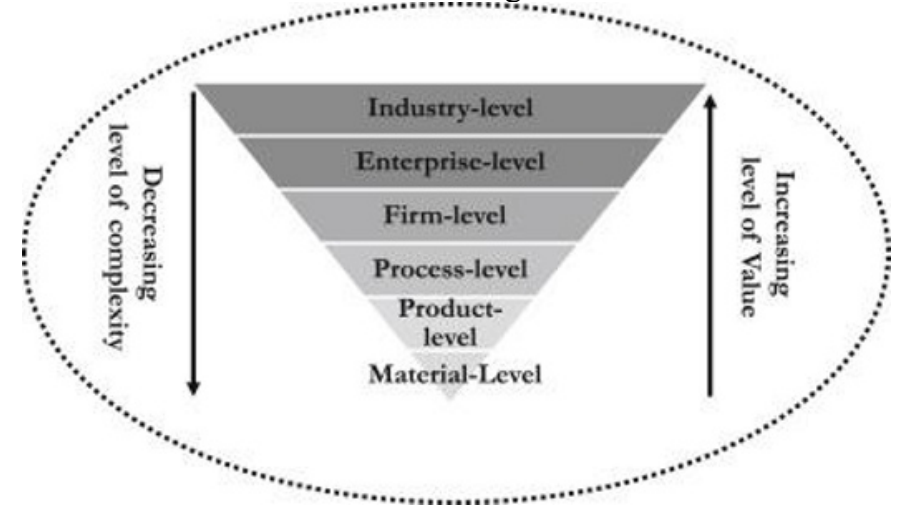

Figure 1. A hierarchal perspective of the value chain and complexity of supply chain systems (Source : [3])

Previously, the industry was localized, cluster-based concept. In present, it morphed to a value chain form that exhibits greater spatial dispersion [7]. Therefore, the industrial levelperspective of the global supply chain can be described as being characterised by increased complexity but also associated with increased levels of value added activities [8]. Production in primary, manufacturing, and service sectors is through these value chains, organized and coordinated on a global basis [9]. Industrial representation of the global value chain has become the world's economy backbone and central nervous system [10].

\subsubsection{Globalization and supply chain management}

Term "supply chain" has become widely recognized primarily as a result of the globalization of manufacturing since the middle of 1990s, particularly the growth of manufacturing in China. Import from China to U.S. grew from about $\$ 45$ billion per year in 1995 to more than $\$ 280$ billion per year in 2006. Globalization has been the cause of need ever since for logistics strategies to deal with complex networks including multiple entities spanning multiple countries with diverse control [11].

The term supply chain management is increasingly used to refer to strategic issues and logistics to refer to tactical and operational problems. This growing association of supply chain management with strategy is reflected in the Council of Logistics Management's changing its name to the Council of Supply Chain Management Professionals in 2005. They strictly differentiate the terms logistics and supply chain management [12]:

- "Logistics is that part of the supply chain process that plans, implements, and controls the efficient, effective forward and reverse flow and storage of goods, 
services, and related information between the point of origin and the point of consumption in order to meet customers' requirements" while

- "Supply Chain Management is the systemic, strategic coordination of the traditional business functions and the tactics across these business functions within a particular company and across businesses within the supply chain for the purposes of improving the long-term performance of the individual companies and the supply chain as a whole."

Many experts have already commented on theme of globalization and supply chains. In the following paragraphs we bring some of the answers.

Greg Shnerer, supply chain and logistics professional based in Toronto, claims that to understanding the role of globalization in the supply chain, it is necessary to first understand what a supply chain is and how it works. A key component of supply chain logistics is global transportation and supply chain would not be possible without it in our global and interconnected world [11].

Greg defines the supply chains as the paths between suppliers and receivers. Then he calls supply chains like the "behind the scenes work" that gets a product from inception all the way into a consumer's hands. In order to reach as many markets as possible, these products must cross international borders. Without supply chains the products that suppliers produce would not efficiently get out into the world markets, therefore they are vital for markets all around the world [11].

Opinion of Ani Mithra, supply chain analyst, is following: Globalization and Supply Chain Management (SCM) are interconnected. In other words, they cannot exist separately, without each other. Globalization gives access to new customers and new sources of procurement. However, the worldwide reach requires the understanding of the different markets, including the potential partners, risks, and regulations [13].

\section{Methodology}

This chapter is devoted to the description of the scientific methods that we used to create the article. We used the following scientific methods: analysis and synthesis.

We used the analysis as a scientific method to divide the research problem into individual parts, elements and their examination in order to reveal their essence. First, we defined the subject of the solution - the global supply chain, then its individual elements to which we want to address - the benefits of being integrated into the global supply chain; also the disadvantages (due to the limited scope of the paper, we decided to include this part in the next paper). Lastly, we wanted to highlight the main mistakes companies do within global supply chain management. The aim of the analysis was therefore to exclude from the whole mass of facts and contexts the main, essential, necessary, which could illuminate the essence of the phenomenon examined.

We used the scientific method of synthesis to find out the links between these earmarked elements, contradictions, their interconnections, and then we could reproduce the phenomenon under investigation with its essential features and relationships. The synthesis of knowledge consisted of joining individual parts into wholes - from the information sources we separated the advantages of joining the global supply chain, also the disadvantages and mistakes in the management of global supply chains and we combined them into individual subchapters in main chapter 3 Results. Through analysis and synthesis, we have discovered new relationships and patterns within global supply chains.

The literature was collected by using various sources, including World Bank report and research papers from database Web of Science. We identified such papers using the keywords "globalization", "supply chain", "supply chain management", "global supply 
chain" and "supply chain and globalization". Subsequently, we gathered the opinions of some experts in the field.

Results represent outputs of studying important publications of the Global Supply Chain Institute at the University of Tennessee and information provided by the professional company DB SCHENKER.

\section{Results}

The results of the paper were divided into the following subchapters: 3.1 Common mistakes in management of global supply chains and 3.2 The main advantages of participation in the global supply chain.

\subsection{Common mistakes in management of global supply chains}

Global supply chains represent new challenges that need to be managed in way to maximize opportunities and minimize risks. And this is precisely the point that many companies trying to break through in global markets have lost sight [14].

For example, a recent study by the University of Tennessee found that $25 \%$ of typical corporate supply chains were not screened for risk management [11].

Fortunately, there are a number of proven ways to reduce risks while exploiting the opportunities of global markets. In the following paragraphs, we have outlined the main mistakes made by companies operating in international markets, as well as the types of how to deal with them and thus reduce the risks involved.

We mainly used the information obtained from company DB SCHENKER, which is professional provider of global transport and logistics network for businesses. It delivers nearly a million shipments annually only by road transport, making it the largest road transporter in Europe. It operates not only in road transport, but also in air, sea and rail transport, in territories such as Europe, Asia, America, Australia and Africa.

\subsubsection{Low transparency of supply chain}

More and more companies feel the need to coordinate the number of carriers and suppliers delivering a wide range of goods from around the world. With the growing volume of import and export, the need for transparency and oversight of logistics activities becomes extremely important. For example, extending the supply chain by replacing a local supplier with a supplier from China may mean increasing the volume of goods in chain, extending delivery times, the need to reassess stock levels, etc. Companies can reduce the risks associated with a complicated international supply chain by involving a logistics partner (3PL - third-party logistics provider), which has distribution centres in place, a functioning global logistics network and contacts to foreign transport service providers. It can be helpful for managing suppliers and setting up processes to keep track of all logistics operations and be able to plan efficiently [15].

\subsubsection{Ignorance of business and delivery conditions (Incoterms)}

A company that starts business in international markets without taking the time to understand the Incoterms and studying its partner's business conditions, is risking serious problems and financial losses. This fact is confirmed by Felix Miletich, Air and Maritime Transport Manager at DB Schenker in Slovakia, statement: "It is incredible how many companies overlook these important details. "Businesses must verify the rights and 
obligations arising from the agreed delivery terms before entering into trade. Otherwise, this can mean an increase in costs but also a significant increase in delivery time. Therefore, before concluding a deal, it is necessary to find out what risks arise from trade and what will be costs about transport. For example, a company choose "cheaper" goods with a CFR Incoterm. In this case, transport and terminal costs have to be reimbursed even if they are set at a high level by business partner. There is no chance to refuse them. Therefore, Miletich recommends to verify in advance the responsibilities of the parties with the partner in detail, to agree everything in writing and to send the information to logistics partner or carrier. If everything is not discussed in detail with the business partner before sending the first shipment, various inconveniences may arise. Businesses will have contradictions between themselves, who has to pay for what and the goods will be detained with the carrier [14].

\subsubsection{Poor forecasting and inventory management}

Nowadays customers expect to receive their shipments on the second or at the latest on the third day of the order. Companies that often solve problems with shipment delays or long transit times, lose business opportunities. If production is outsourced, for example, to China, delivery times can be quite long and it is worth considering anything that will help to companies shorten this time [13]. We recommend focusing on forecasting, solid inventory management, and searching for alternative suppliers. It may also be helpful to work with an experienced logistics provider, which has its own representation in the country, knows local legislation and processes that can help to reduce the risk of shipment delays, for example, by avoiding problems with customs authorities.

\subsubsection{Excessive cost on urgent shipments}

There exists some rule: Companies, that rely $100 \%$ on shipping by sea transport, usually do not have a backup logistics plan. Occasionally there may be a shipment that misses the time of embarkation or needs faster delivery. Miletich claims, at that time, most companies will automatically choose for the most expensive option - air travel, without even considering other alternatives. However, there are other possibilities. For example, rail transport from Asia to Europe, various combinations of air and sea transport, but also the possibility of using preferential rates for air transport if the client gives the carrier the opportunity to deliver the goods within a certain time span. Shippers, who are sure about the requirements for the transport time and do not take unnecessarily the fastest and most expensive option immediately, have the best position. A company that cannot wait three weeks for a shipment, but 12 days yes, can get significantly better prices than a company that requires 'urgent delivery'. To companies, we recommend to provide much information to their shipping company. There is a greater chance to receive optimal price solution in terms of both transport time and cost [14].

\subsubsection{No action plan in case of supply chain disruption}

Anything can happen during the shipment of consignment to the buyer - for example, a factory of the supplier will burn; airport or port staff shall declare a strike or problems with customs clearance. Similar situations can have a serious impact on a company, even if they happen in country thousands of kilometres away [16]. To avoid or prevent supply problems, there is a need to go beyond suppliers Tier 1 knowledge. [17] claim that companies should take a closer look at the solvency of Tier 2 and Tier 3 suppliers that supply their main suppliers. If businesses want to manage their international supply chain effectively, they 
should know where each component comes from and who produces it. If there is a problem with one of the suppliers, the logistics partner may also be helpful in creating a backup plan [18].

\subsection{The main advantages of participation in the global supply chain}

Definitely, the global supply chain is not without disadvantages. These will be dealt with in the future research. However, the positive benefits that a global supply chain can bring far outweigh any potential drawbacks. We introduce, in our opinion, the top 10 benefits of participation in the global supply chain, but there are many, many more.

\subsubsection{Availability of excellent products}

Here is a possibility to source excellent products completed to the highest standard of quality controls quickly and efficiently. Global supply is extremely competitive and it is possible to obtain a really good price for supplies that will all be produced to excellent standards, without even having to search widely [19].

\subsubsection{Reducing costs}

Companies involved in a global supply chain are able to push their costs right down and therefore ensure stable position on the market and the economic viability of their business. Global supply chains became one of the first methods for using the cost reduction activities in supply chains [20].

\subsubsection{Motivation to be better in business}

In the case, the businesses that previously only acted locally in the domestic market, are involved in the global supply chain, they are forced to improve their performance. If companies, operating within developing countries or those such as India and China, fail in their deliveries, there are a myriad of other businesses that will deliver the goods to customer. This means that there is a real incentive to do things right, at the first time and all the time [21].

\subsubsection{Reducing amount of stock}

There is a possibility to reduce the amount of stock that it is necessary to retain, if companies have sufficient contacts and suppliers internationally. It means that they can save costs in terms of storage, thefts, transporting goods etc. Reduction of sum of these costs certainly helps sharpen the competitive edge that comes with a global supply chain [22].

\subsubsection{Securing of almost any item in easy way}

Thanks to the global supply chain, it is now easy to secure almost every item because there is a likelihood that it is produced or manufactured somewhere in the world. In the past, any item that was not a standard item, from a standard range could take ages to produce. Nowadays, it can simply be bought from the country where it has been made [23]. 


\subsubsection{Continuous operation of the supply chain}

The chain never sleeps and is constantly on the go - it really does operate on a $24 / 7$ basis, simply because of the time differences in different countries. People within supply chain are working to meet the supply chain requirements on different continents and at different times [11].

\subsubsection{New opportunities and markets}

Joining the global supply chain also brings new opportunities for markets. If a company decides to obtain its items from China, for example, it is likely that it will also want to discover other markets that it would like to penetrate because it has already established sources in China. It is almost as if once a company has taken the first step to source supplies globally, new markets and opportunities follow [23,24].

\subsubsection{Learning from others}

Business is done differently in different parts of the world. One of the most interesting factors of the global supply chain is that companies can learn from others, because they cooperate with businesses from around the world. Therefore, it is possible to learn new ways of doing business, new production methods and new distribution methods, if representatives of companies keep an open mind and have a willingness to learn [11].

\subsubsection{Flexibility}

A global supply chain has to be flexible or will be simply applied. With a global supply chain the flexibility is always given a higher priority and as such, flexibility within the chain is maximised, allowing for the chain to be as effective as possible [11].

\subsubsection{Greater chance to survive}

Companies within framework of global supply chain have a chance of success and being able to even grow during the economic downturn. If they are not part of it, their chances of survival are lower. There exists a simple rule - if company is not operating within a global supply chain framework, certainly it is well behind those who are [23].

\section{Conclusions}

The aims of the paper, we set out at the beginning, were following: to define the concept of supply chain and supply chain management; to list what advantages arising from participation in global supply chain and finally, to refer the mistakes made by companies operating in international markets in supply chain management.

Basic definitions of supply chain and supply chain management are provided in the first chapter Introduction. The relationship between supply chain management and globalization is also described. In the second chapter Methodology, where the methods used to process the paper are listed. It is followed by the chapter Results.

Results are divided into two sections: Common mistakes in management of global supply chains and Main advantages of global supply chains.

Firstly, we present the main problems and recommendations for businesses. The results summarized in brief: 
1. Many companies lack a transparent supply chain; recommendation: to include a logistics partner.

2. Businesses are overlooking important details about Incoterms and partner's business conditions; recommendation: to verify in advance the responsibilities of the parties with the partner in detail, to agree everything in writing and to send the information to logistics partner or carrier.

3. Companies solve problems with shipment delays or long transit times; recommendation: to focus on forecasting, solid inventory management, and searching for alternative suppliers, also to work with an experienced logistics provider.

4. Companies rely $100 \%$ on maritime transport and choose the most expensive option - air transport in the event of failure; recommendation: to consider other alternatives, for example rail transport from Asia to Europe, various combinations of air and sea transport and others (listed above).

5. Companies are usually not prepared for unexpected events can happen during the shipment of consignment to the buyer; recommendation: to take a closer look at the solvency of Tier 2 and Tier 3 suppliers that supply their main suppliers, to know where each component comes from and who produces it, to create a backup plan with the logistics partner.

In the next section, we wanted to highlight the main benefits businesses can gain from participating in the global supply chain.

Because global supply is extremely competitive, there is a possibility to source excellent products completed to the highest standard of quality controls quickly and efficiently. Companies involved in the global logistics chain are able to push their costs down, resulting in a stable market position and increased competitiveness. If businesses that previously only acted locally in the domestic market are involved in the global supply chain, they are forced to improve their performance. Also, companies can learn from others, because they cooperate with businesses from around the world. Therefore, it is possible to learn new ways of doing business, new production methods and new distribution methods, if representatives of companies keep an open mind and have a willingness to learn. Last but not least, there is a chance of success and being able to even grow during the economic downturn. There is no doubt that involving a business in the global supply chain is a very good choice if companies want to grow and increase their competitiveness. Of course, this decision also has its drawbacks, but these will be dealt with in further research (paper). Especially for global supply chains, there exist geographical distance which magnifies uncertainties and creates challenges such as unexpected disruptions [25]. However, the positive benefits that a global supply chain can bring far outweigh any potential drawbacks.

Due to the limited scope of the paper, we have decided to publish only part of the findings. Other information will become the basis for the next paper. In the next research, we want to focus on following: the main disadvantages of participation in global supply chains; mapping supply chain; supply chain planning system model.

\section{Acknowledgment}

This paper is an output of scientific project VEGA no. 1/0718/18: The impact of psychographic aspects of pricing on the marketing strategy of companies across products and markets. 


\section{References}

1. M. A. Khan, M. Baseer, Globalization of Logistics and Supply Chain Management. Proceedings of International Conference on Industrial Engineering and Operations Management. Kuala Lumpur, Malaysia (2016)

2. L. Horvath, Collaboration: The key to value creation in supply chain management. Supply Chain Management: An International Journal 6, 205-207 (2001)

3. A. Acquaye, KS. Feng, E. Oppon, S. Salhi, T. Ibn-Mohammed, A. Genovese, K. Hubacek, Measuring the environmental sustainability performance of global supply chains: A multi-regional input-output analysis for carbon, sulphur oxide and water footprints. Journal of Environmental Management 187, 571-585 (2017)

4. DM. Lambert, MG. Enz, Issues in Supply Chain Management: Progress and potential. Industrial Marketing Management 62, 1-16 (2017)

5. H. Min, GG. Zhou, Supply chain modelling: past, present and future. Computers \& Industrial Engineering 43, 231-249 (2002)

6. K. Kemppainen, A. P. Vepsäläinen, Trends in industrial supply chains and networks. International Journal of Physical Distribution \& Logistics Management 33, 701-719 (2003)

7. S. Ponte, T. Sturgeon, Explaining governance in global value chains: A modular theory-building effort. Review of International Political Economy 21, 195-223 (2014)

8. G. Gereffi, J. Humphrey, T. Sturgeon, The governance of global value chains. Review of International Political Economy 12, 78-104 (2005)

9. HWC, Yeung, NM. Coe, Toward a Dynamic Theory of Global Production Networks. Economic Geography 91, 29-58 (2015)

10. O. Cattaneo, G. Gereffi, C. Staritz, Global value chains in a postcrisis world: A development perspective. World Bank Publications, 1-396 (2010)

11. T. Stank, M. Burnette, P. Dittmann, Global supply chains (A white paper by the Global Supply Chain Institute). Game-changing trends in supply chain series 4, 1-52 (2014)

12. S. Min, ZG. Zacharia, CD. Smith, Defining Supply Chain Management: In the Past, Present, and Future. Journal of Business Logistics 40, 44-55 (2019)

13. J. T. Mentzer, M. B. Myers, T. P. Stank. Handbook of global supply chain management. (SAGE Publications, California, 2006)

14. Chyby v riadeni dodavatelskych retazcov. (2017). Retrieved 10.09.2019 from https://logistickesluzby.sk/chyby-v-riadeni-dodavatelskych-retazcov/

15. D. M. Lambert, M. C. Cooper, Issues in Supply Chain Management. Industrial Marketing Management 29, 65-83 (2000)

16. G. Graham, K. Coutts, N. Gibson, J. Buchanan, The Macro-Economic Impact of Brexit: Using the CBR Macro-Economic Model of the UK Economy (UKMOD). Journal of Self-Governance and Management Economics 6, 7-49 (2018)

17. P. Trkman, K. Mccormack, Supply Chain Risk in Turbulent Environments - A Conceptual Model for Managing Supply Chain Network Risk. International Journal of Production Economics 119, 247-258 (2009)

18. J. Kliestikova, K. Janoskova, Branding with understanding: how national profile of consumer influences brand value perception. Marketing and management of innovations, 149-157 (2017) 
19. P. Durana, P. Kral, V. Stehel, G. Lazaroiu, W. Sroka, Quality Culture of Manufacturing Enterprises: A Possible Way to Adaptation to Industry 4.0. Social Sciences 8, 1-25 (2019)

20. M. Dobrodolac, L. Svadlenka, M. Cubranic-Dobrodolac, S. Cicevic, B. Stanivukovic, A model for the comparison of business units. Personnel Review 47, 150-165 (2018)

21. J. Salaga, V. Bartosova, E. Kicova, Economic Value Added as a measurement tool of financial performance. Procedia Economics and Finance 26, 484-489 (2015)

22. W. Delfmann, S. Albers, Supply Chain Management in the Global Context. Seminars fur Allgemeine Betriebswirtschaftslehre, Betriebswirtschaftliche Planung und Logistik (2000)

23. M. Burnette, CH. Autry, End-to-end supply chain planning framework and key concepts (A white paper by the Global Supply Chain Institute). Supply chain strategy series 3, 1-44 (2019)

24. L. Gajanova, M. Nadanyiova, J. Kliestikova, J. Olah, The potential of using Bluetoothbased system as a part of proximity marketing in the Slovak Republic. Marketing and management of innovations, 239-252 (2019)

25. TM. Choi, X. Wen, XT. Sun, SH. Chung, The mean-variance approach for global supply chain risk analysis with air logistics in the blockchain technology era. Transportation Research Part E-logistics and Transportation Review 127, 178-191 (2019) 